\title{
FABRICATION OF TITANIUM ORTHORHOMBIC ALLOY SPHERICAL POWDERS BY MECHANICAL ALLOYING AND PLASMA SPHEROIDIZATION FOR APPLICATION IN ADDITIVE MANUFACTURING PROCESSES
}

\author{
Igor POLOZOV, Nikolay RAZUMOV, Tagir MAKHMUTOV, Anatoliy POPOVICH \\ Peter the Great St, Petersburg Polytechnic University, St. Petersburg, Russian Federation \\ polozovia@spbstu.ru
}

https://doi.org/10.37904/metal.2019.931

\begin{abstract}
The microstructural and phase evolution of the powders at different times of milling and after treatment in the flow of the thermal plasma were studied. The X-Ray Diffraction and Scanning Electron Microscopy studies showed that increasing milling time up to $12 \mathrm{~h}$ improves chemical homogeneity of the powders and promotes the formation of B2/ $\beta$-phase solid solution, while at shorter milling times the powders consist of a highly inhomogeneous layered structure with HPC- and BCC-crystal structures. The plasma spheroidization of irregular powders after MA resulted in highly-spherical powders of the orthorhombic alloy with a homogeneous chemical composition consisting of dendritic B2-phase. The fabricated spherical powders can be utilized in Additive Manufacturing processes to fabricate intermetallic components.
\end{abstract}

Keywords: Mechanical alloying, plasma spheroidization, titanium alloy, intermetallic

\section{INTRODUCTION}

Titanium orthorhombic alloys based on $\mathrm{Ti}_{2} \mathrm{AlNb}$-phase are considered to be excellent candidates for replacing nickel-based superalloys due to their physical and mechanical properties, e.g. high yield strength, creep resistance and a working temperature up to $650^{\circ} \mathrm{C}[1,2]$. Orthorhombic titanium alloys demonstrate enhanced ductility compared to other titanium aluminides alloys. Ti2 AlNb-based alloys are of particular interest for Additive Manufacturing (AM) due to the high cost of production by conventional techniques.

At the same time, the availability of titanium intermetallic powders appropriate for their application in AM are very limited. A general requirement for powders used in $A M$ is a spherical particle shape, chemical homogeneity, and a uniform particle size. Mostly the powder for AM are produced by atomization techniques [3], but in case of titanium intermetallic alloys this method faces a lot of difficulties to achieve high-quality powders for AM. One of the alternative ways to produce homogeneous spherical powders is to use a combination of mechanical alloying (MA) and plasma spheroidization (PS) processes. Powders obtained my MA have an irregular particle shape. PS process can be used to give the powders spherical shape. High temperature treatment in a plasma jet leads to rapid melting and solidification of the particles. By controlling parameters such as feed rate, the flow rate of plasma gas and plasma power flux, it is possible to obtain particles of a given composition of alloys with spherical form [4].

Ti-22Al-25Nb (at\%) alloy is considered as a prototypical alloy among Ti2AINb-based alloys [5]. However, this alloy has some drawbacks in terms of creep and oxidation resistance. One approach is to add $\beta$-phase stabilizing elements that are dissolved in the O-phase. For example, adding Mo is known to improve the oxidation and creep resistance. Mo and $\mathrm{Si}$ if added combined improve the high temperature oxidation resistance of $\mathrm{Ti}_{3} \mathrm{Al}$ alloys compared to that of alloying alone. $\mathrm{Zr}$ addition improves the creep strength and the oxidation resistance [6].

In this paper, $\mathrm{Ti}-22 \mathrm{Al}-25 \mathrm{Nb}-0.3 \mathrm{Mo}-1 \mathrm{Zr}-0.3 \mathrm{Si}-0.2 \mathrm{Hf}-0.4 \mathrm{Ta}$ (at\%) alloy powders were fabricated from elemental powders by MA for different milling times followed by PS to obtain spherical powder particles. The phase 
evolution and the alloy formation dependencies on the milling time during MA and after PS were studied. It was established that increasing the milling time improves the homogeneity of the powders and promotes the formation of $B 2 / \beta$-phase and the PS process results in the spherical powders with homogenic distribution of elements, consisting of dendritic B2-phase.

\section{MATERIALS AND METHODS}

The blended elemental powders of $\mathrm{Ti}, \mathrm{Al}, \mathrm{Nb}, \mathrm{Mo}, \mathrm{Zr}, \mathrm{Si}, \mathrm{Hf}$, and $\mathrm{Ta}$ (with $99.9 \%$ purity) were mixed to obtain the composition of with $\mathrm{Ti}-22 \mathrm{Al}-25 \mathrm{Nb}-0.3 \mathrm{Mo}-1 \mathrm{Zr}-0.3 \mathrm{Si}-0.2 \mathrm{Hf}-0.4 \mathrm{Ta}$ (at $\%$ ) and then mechanically alloyed using a planetary mill Fritsch Pulverisette 4 in the argon atmosphere for 4, 8, $12 \mathrm{~h}$. The milling of the powders was stopped every $45 \mathrm{~min}$ for $15 \mathrm{~min}$ to prevent overheating of the powders. Steel balls of $10 \mathrm{~mm}$ diameter were used as the milling media with the ball-to-powder ratio of 20:1. The main disk rotation speed was $200 \mathrm{rpm}$ (clockwise direction) and the bowl rotation speed was $400 \mathrm{rpm}$ (counterclockwise direction). After mechanical alloying the obtained powders were sieved using a $125 \mu \mathrm{m}$ sieve and then spheroidized in the Tekna TEK-15 plant with the inductively coupled plasma at $15 \mathrm{~kW}$ plasma torch power. The Ar-He gas was used as the plasma forming gas. The powder feeding rate was set to $15 \mathrm{~g} / \mathrm{min}$. TESCAN Mira $3 \mathrm{LMU}$ scanning electron microscope (SEM) with secondary electrons (SE) and backscattered electrons (BSE) was utilized for the microstructural characterization of the powders. Energy-dispersive X-ray spectroscopy (EDS) option was used for local chemical analysis of the samples. The phase composition was analyzed with a Bruker D8 Advance X-ray diffraction $(\mathrm{XRD})$ meter using Cu-Ka $(\lambda=0.15418 \mathrm{~nm})$ irradiation.

\section{RESULTS AND DISCUSSION}

Figure 1 shows the BSE-SEM images of Ti-22Al-25Nb-0.3Mo-1Zr-0.3Si-0.2Hf-0.4Ta powders obtained after MA for 4, 8, and $12 \mathrm{~h}$. The powders obtained by MA have irregular particles' shape typical for milling processes. There are visible white areas on the particles' surfaces corresponding to undissolved alloying elements like $\mathrm{Nb}, \mathrm{Ta}, \mathrm{Mo}, \mathrm{Zr}$, Hf. As can be seen from BSE-SEM images of particles sections (Figure 2), the powders obtained by MA are characterized by inhomogenical distribution of elements and feature layered microstructure typical for MA powders [7]. Increasing the milling time improves the homogeneity of the powders. The EDS measurements of the powder particles obtained after MA for $12 \mathrm{~h}$ showed that the average composition corresponds to the initial elemental powder blend. However, there has been a slight pick-up of $\mathrm{Fe}$ (up to 1.2 $w t \%)$ during MA due to the use of steel milling balls and bowls.
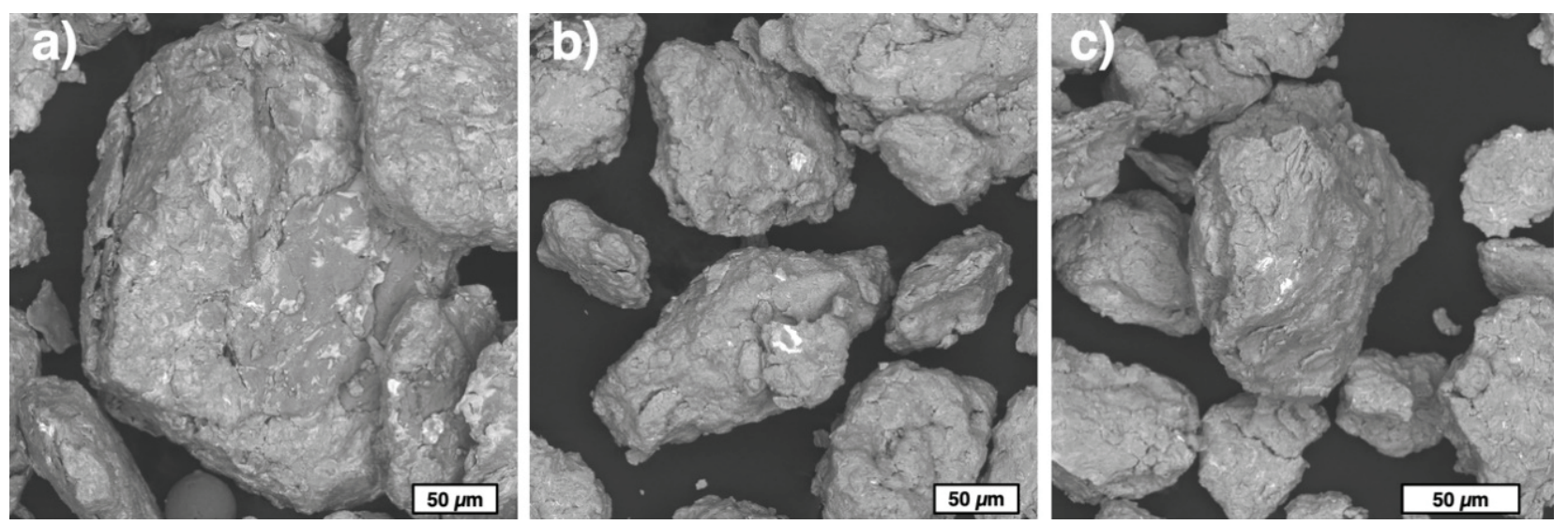

Figure $1 \mathrm{BSE}-\mathrm{SEM}$ images of Ti-22AI-25Nb-0.3Mo-1Zr-0.3Si-0.2Hf-0.4Ta powders obtained by MA with the milling time of $4 \mathrm{~h}(\mathrm{a}), 8 \mathrm{~h}(\mathrm{~b})$, and $12 \mathrm{~h}(\mathrm{c})$ 

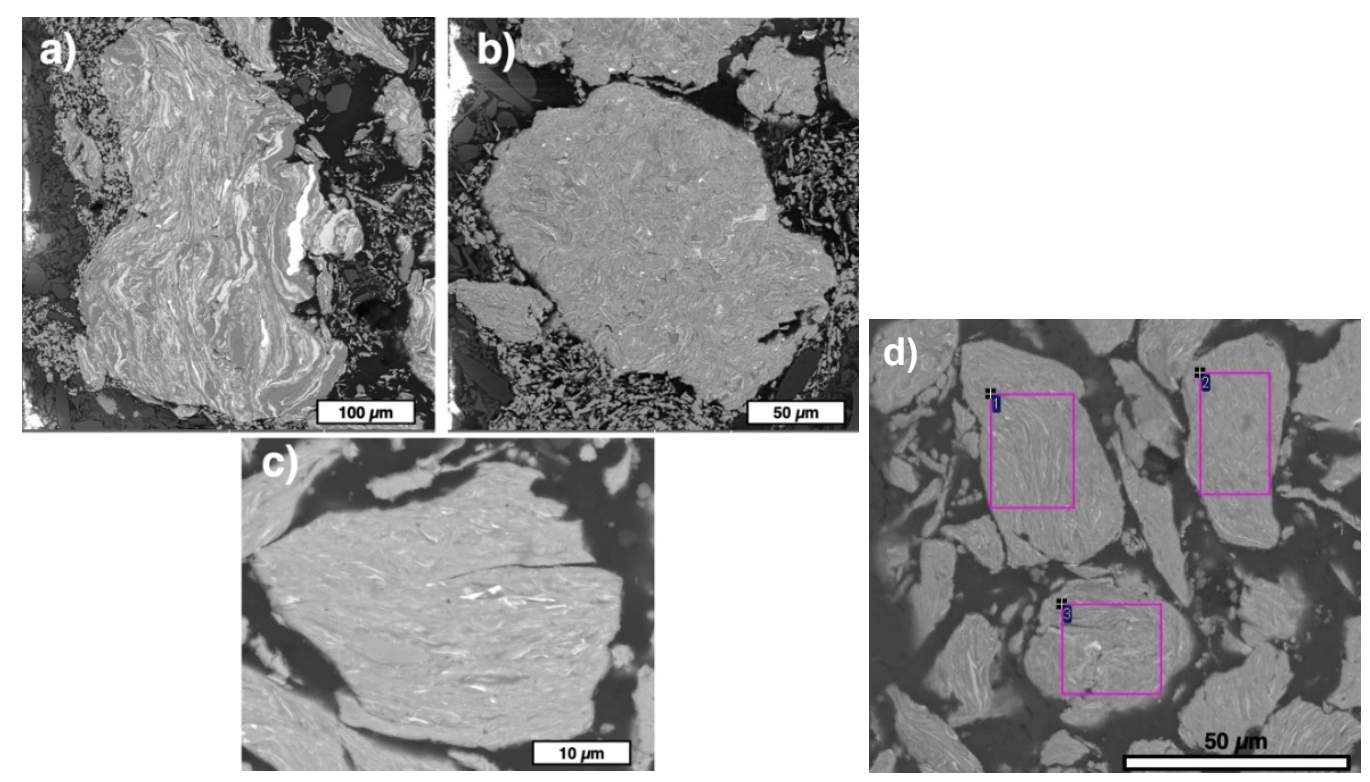

Figure 2 BSE-SEM images of Ti-22Al-25Nb-0.3Mo-1Zr-0.3Si-0.2Hf-0.4Ta powder particles sections obtained by MA with the milling time of $4 \mathrm{~h}(\mathrm{a}), 8 \mathrm{~h}(\mathrm{~b}), 12 \mathrm{~h}(\mathrm{c})$, and areas for EDS measurements for particles after $12 \mathrm{~h}$ milling time $(\mathrm{d})$

Table 1 The results of EDS measurements for the areas shown in Figure $\mathbf{2} \mathbf{d}$

\begin{tabular}{|c|c|c|c|c|c|c|c|c|c|}
\hline \multirow{2}{*}{ Area } & \multicolumn{9}{|c|}{ Element content (wt\%) } \\
\cline { 2 - 11 } & $\mathbf{T i}$ & $\mathbf{A l}$ & $\mathbf{N b}$ & $\mathbf{S i}$ & $\mathbf{Z r}$ & $\mathbf{M o}$ & $\mathbf{H f}$ & $\mathbf{T a}$ & $\mathbf{F e}$ \\
\hline 1 & 43.06 & 11.44 & 37.74 & 2.92 & 2.01 & 0.15 & 1.66 & 0.44 & 0.58 \\
\hline 2 & 43.52 & 11.35 & 38.10 & 2.26 & 2.00 & 0.14 & 0.48 & 0.95 & 1.20 \\
\hline 3 & 42.01 & 12.15 & 39.64 & 2.10 & 2.20 & 0.17 & 0.96 & 0.53 & 0.24 \\
\hline
\end{tabular}

Table 1 shows the XRD results of the powders obtained by MA at different milling times. After milling for 4 hours the XRD shows the presence of a body-centered cubic (BCC) phase corresponding to $\mathrm{Nb} / \beta-\mathrm{Ti}$, a hexagonal closed-packed (HCP) phase corresponding to $\alpha-\mathrm{Ti}$, and a small amount of face-centered cubic (FCC) phase corresponding to Al. This suggests that $4 \mathrm{~h}$ of milling time was not enough for the diffusion of elements and the formation of the alloy. After $8 \mathrm{~h}$ of milling the Al peaks disappear and the HCP-phase peaks decrease. Increasing the milling time leads to broadening and lowering of the peaks along with the decrease of the ratio of the peaks' intensities to the background intensity. This suggests the formation of $\beta / B 2$-phase and ordering of the solid solution (B2).

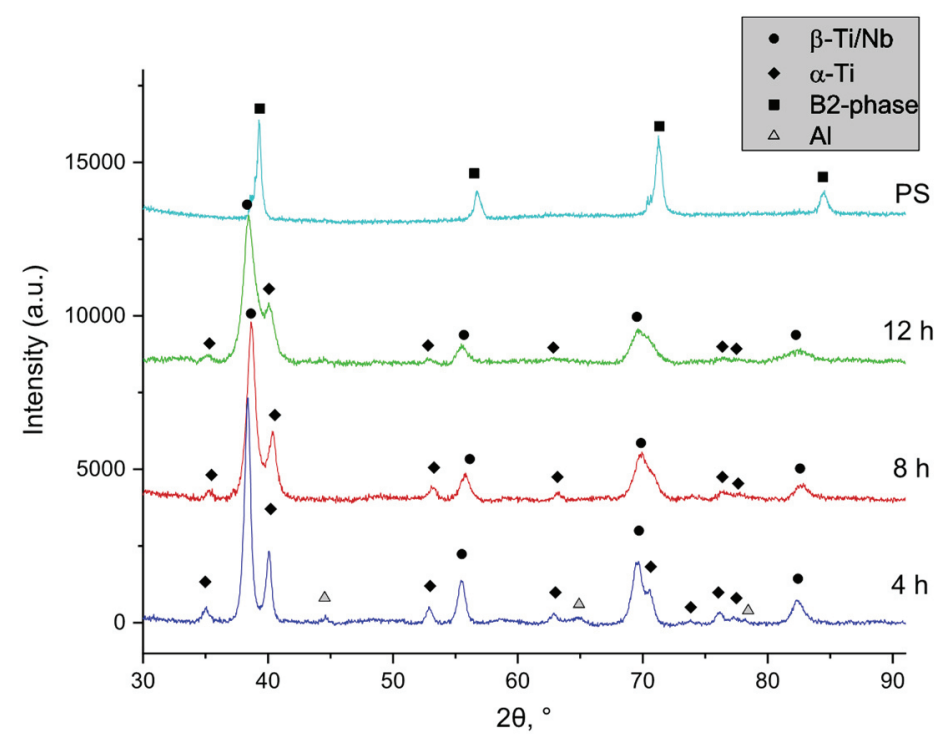

Figure 3 The XRD results of Ti-22Al-25Nb-0.3Mo-1Zr$0.3 \mathrm{Si}-0.2 \mathrm{Hf}-0.4 \mathrm{Ta}$ powders obtained by mechanical alloying at different milling times and after plasma spheroidization 
Figure 4 shows the SEM-image of the powder particles obtained after PS. The powder particles treated in a plasma jet have spherical shape and dendritic microstructure. According to the XRD results, the powder after PS consists only of B2-phase which was a result of rapid cooling during the $\mathrm{PS}$ process. The true density of the powders measured by the pycnometer test was $5.12 \mathrm{~g} / \mathrm{cm}^{3}$ which is close to the values of titanium orthorhombic alloys [8]. The chemical composition of the powder particles after
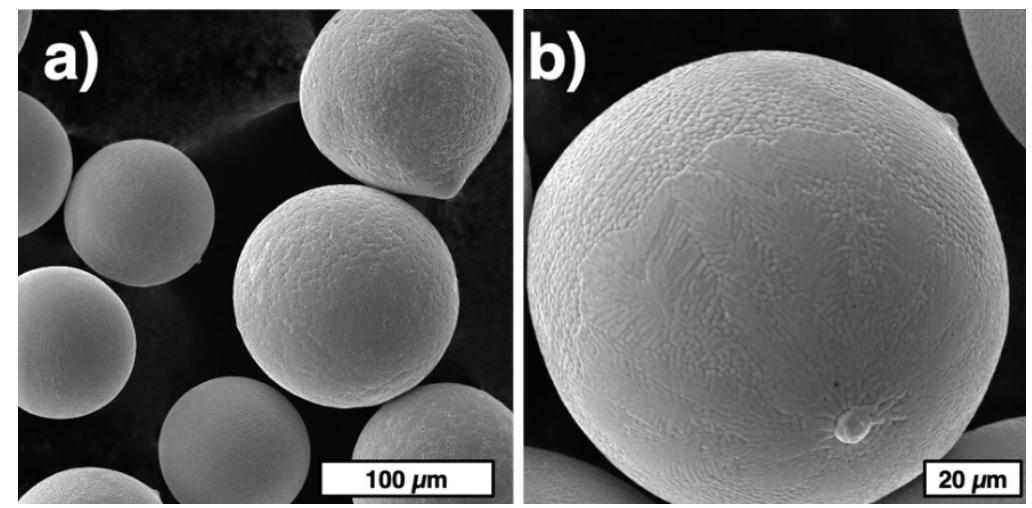

Figure 4 SEM-images of Ti-22Al-25Nb-0.3Mo-1Zr-0.3Si-0.2Hf0.4Ta powder particles after plasma spheroidization

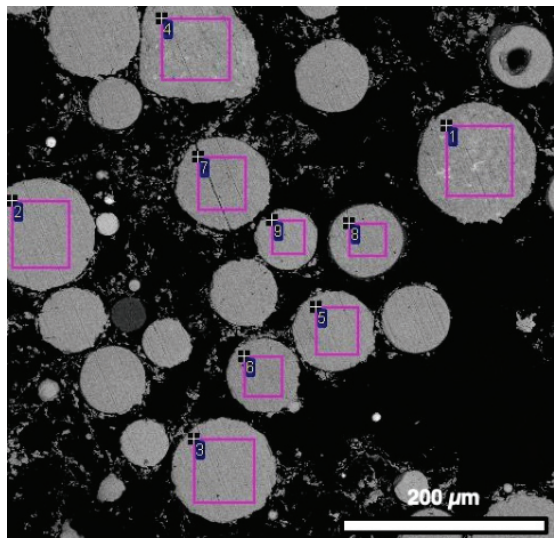

Figure 5 BSE-SEM images of the powder particles polished crosssections and the areas used for EDS measurements

Figure 6 BSE-SEM image of the particle polished cross-section for the powder after PS and elements distribution
PS was measured using the EDS method at the particles crosssections as shown in Figure 5 . The resultant composition was the following (in at\%): $\mathrm{Ti}-49.8 \pm 0.8 ; \mathrm{Al}-24.3 \pm 1.5 ; \mathrm{Nb}-22.6 \pm 0.6$; $\mathrm{Mo}-$ $0.1 \pm 0.1 ; \mathrm{Hf}-0.3 \pm 0.1 ; \mathrm{Ta}-0.3 \pm 0.1 ; \mathrm{Zr}-1.5 \pm 0.1 ; \mathrm{Si}-0.8 \pm 0.1 ; \mathrm{Fe}$ $-0.9 \pm 0.4$.

The EDS maps for elements distribution in the powder particle after PS are shown in Figure 6. It can be seen that the chemical homogeneity significantly improved after PS compared to the initial powders obtained by MA. After the PS process the alloying elements are evenly distributed in the particle.
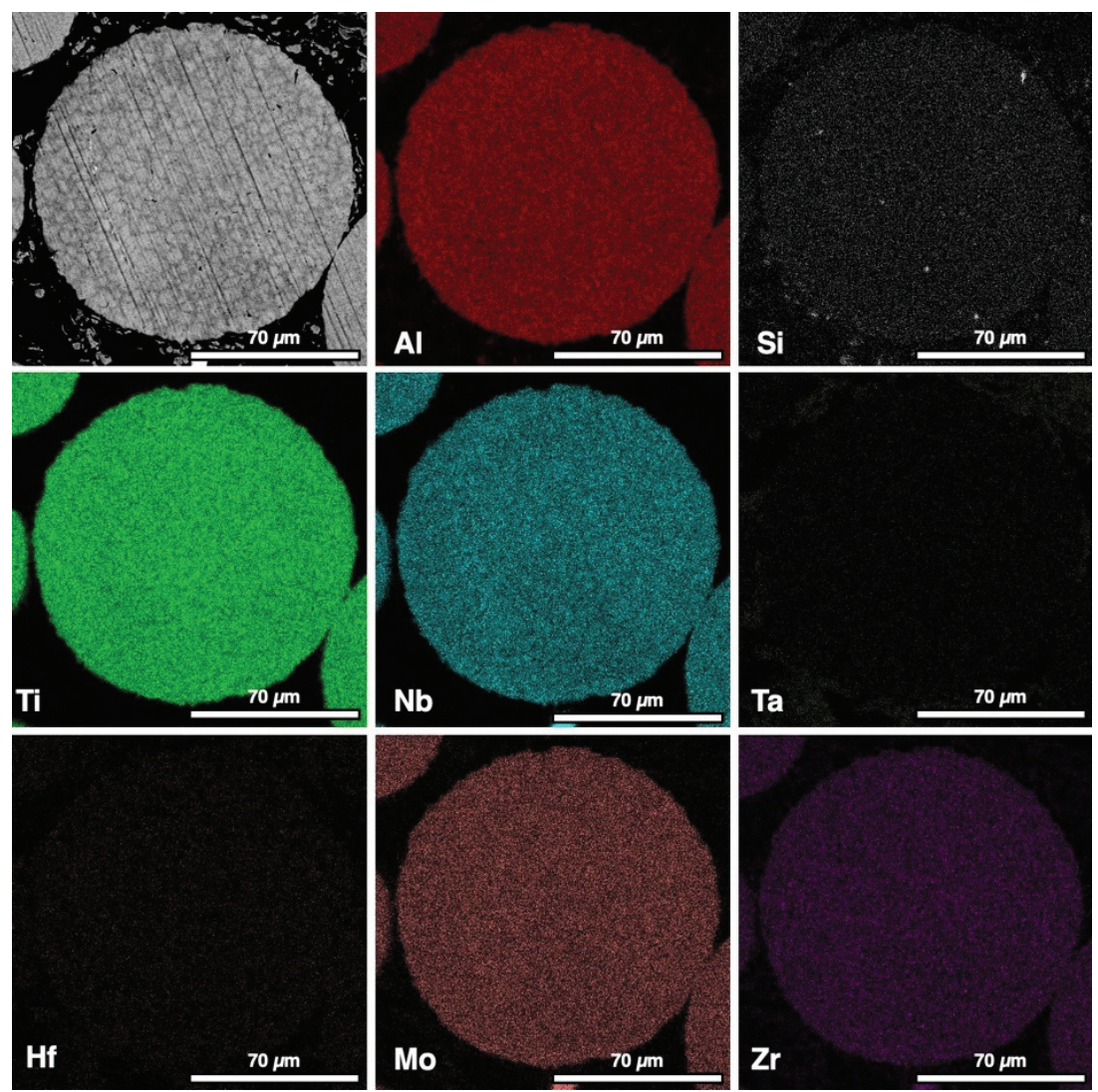


\section{CONCLUSIONS}

In the present work, the powders of intermetallic orthorhombic alloy Ti-22Al-25Nb-0.3Mo-1Zr-0.3Si-0.2Hf$0.4 \mathrm{Ta}(\mathrm{at} \%)$ were fabricated by mechanical alloying and plasma spheroidization processes. The high sphericity of the powder particles and the homogeneous chemical distribution allow the powder to be used in Additive Manufacturing processes such as Selective Laser Melting or Direct Energy Deposition. Additional screening is required depending on the used AM technology.

Increasing of the mechanical alloying time up to $12 \mathrm{~h}$ promotes the formation of $\mathrm{B} 2 / \beta$ solid solution with a more homogeneous chemical distribution. However, mechanical alloying leads to the Fe contamination from the grinding media.

Plasma spheroidization of the mechanically alloyed powders results in the spherical powder particles with a homogeneous chemical distribution. The obtained powders consist of B2 solid solution with the dendritic microstructure.

\section{ACKNOWLEDGEMENTS}

This research was supported by Russian Science Foundation grant (project No 18-13-00111).

\section{REFERENCES}

[1] KUMPFERT, J. Intermetallic alloys based on orthorhombic titanium aluminide. Advanced Engineering Materials. 2001. vol. 3, no. 11, pp. 851-864.

[2] MAŁECKA, J. Investigation of the oxidation behavior of orthorhombic Ti 2 AINb alloy. Journal of Materials Engineering and Performance. 2015. vol. 24, no. 5, pp. 1834-1840.

[3] SUN, P., FANG, Z. Z., XIA, Y., ZHANG, Y. and ZHOU, C. A novel method for production of spherical Ti-6Al-4V powder for additive manufacturing. Powder Technology. 2016. vol. 301, pp. 331-335.

[4] RAZUMOV, N. G., POPOVICH, A. A. and WANG, Q. Thermal plasma spheroidization of high-nitrogen stainless steel powder alloys synthesized by mechanical alloying. Metals and Materials International. 2018. vol. 24, no. 2, pp. 363-370.

[5] GRIGORIEV, A., POLOZOV, I., SUFIIAROV, V. and POPOVICH, A. In-situ synthesis of Ti2AINb-based intermetallic alloy by selective laser melting. Journal of Alloys and Compounds. 2017. vol. 704, pp. 434-442.

[6] HE, Yong-sheng et al. Microstructural evolution and creep deformation behavior of novel Ti- 22Al- 25Nb- $1 \mathrm{Mo}-$ $1 \mathrm{~V}-1 \mathrm{Zr}-0.2 \mathrm{Si}$ (at\%) orthorhombic alloy. Transactions of Nonferrous Metals Society of China. 2019. vol. 29, no. 2, pp. 313-321.

[7] GONCHAROV, I. S. et al. Synthesis of Nb-based powder alloy by mechanical alloying and plasma spheroidization processes for additive manufacturing. Materials Letters. 2019. vol. 245, pp. 188-191.

[8] JIA, J., ZHANG, K., LIU, L. and WU, F. Hot deformation behavior and processing map of a powder metallurgy Ti22Al-25Nb alloy. Journal of Alloys and Compounds. 2014. vol. 600, pp. 215-221. 